\title{
O PAPEL DO PSICÓLOGO JURÍDICO NA VIOLÊNCIA INTRAFAMILAR: POSSÍVEIS ARTICULAÇÕES
}

\author{
Taís Burin Cesca \\ Universidade Luterana do Brasil
}

\begin{abstract}
RESUMO: Este artigo se propõe abordar a temática da violência intrafamiliar contra crianças, principalmente no que se refere às questões jurídicas, fazendo uma interseção entre Direito/Psicologia e demais instâncias envolvidas, mostrando, dessa forma, a necessidade de um trabalho interdisciplinar no combate aos maus-tratos. A partir disso, traz informações sobre essa nova área de atuação do Psicólogo que é a Psicologia Jurídica, uma área ainda pouco conhecida, porém de extrema importância para a atuação do profissional Psi.

PALAVRAS-CHAVE: maus-tratos, Psicologia Jurídica, Direito, interdisciplinaridade.
\end{abstract}

\section{THE ROLE OF LEGAL PSYCHOLOGY ON INTRA-FAMILY VIOLENCE: POSSIBLE ARTICULATIONS}

ABSTRACT: This article is proposed to approach the theme of intra-family violence against children, mainly on the topic about Law questions, making an intersection between Law and Psychology and further matters involved showing, this way, the need for an interdiscilpinary job against bad treating. From then on it brings information on this new field of work of the Psychologist which is Law psychology, still a little known field, however of extreme importance for the job of the Psy professional.

KEY-WORDS - bad treating, Legal Psychology, Law, interdisciplinarity

Dentre os diversos ramos que a psicologia jurídica pode abordar, o presente artigo trata do papel do psicólogo forense no que se refere à violência intrafamiliar, bem como sua articulação com demais instâncias envolvidas.

O campo da violência doméstica é um "terreno movediço", como afirma Miranda (1998), em que se mesclam fantasia e realidade, cena que causa horror e curiosidade. Diante do número imenso de variáveis culturais e psíquicas, torna-se muito complexa a tarefa de bem lidar com este problema.

O estudo da violência em suas causas, conseqüências, objetivos, justificativas, ganhou atualidade, parecendo depender desta compreensão a possibilidade de sobrevivência da humanidade e a construção de alternativas para um futuro melhor.

Pode-se pensar na violência intrafamiliar como toda ação ou omissão que prejudique o bemestar, a integridade física, psicológica ou a liberdade e o direito ao pleno desenvolvimento de outro membro da família. Pode ser cometida dentro ou fora de casa por algum membro da família, incluindo pessoas que passam a assumir função parental, ainda que sem laços de consangüinidade, e em relação de poder à outra. Portanto, quando se fala de violência intrafamiliar deve-se conside- rar qualquer tipo de relação de abuso praticado no contexto privado da família contra qualquer um de seus membros. Deve-se ainda ressaltar que o conceito de violência intrafamiliar não se refere apenas ao espaço físico onde a violência ocorre, mas também às relações em que se constrói e efetua.

No que se refere à Psicologia Jurídica seu surgimento é bastante recente. A participação do psicólogo nas questões judiciais começou em 1980, no Tribunal de Justiça do Estado de São Paulo, quando um grupo de psicólogos voluntários orientava pessoas que lhes eram encaminhadas pelo Serviço Social, basicamente apoio a questões familiares, tendo como objetivo principal sua reestruturação e manutenção da criança no lar. Mais tarde, a Lei $\mathrm{n}^{\circ} 500$ do CPC instituiu a contratação do Psicólogo, a título precário, por um ano, podendo ser recontratado após esse período. Em 1985, o presidente do Tribunal de Justiça apresentou à Assembléia Legislativa um projeto criando o cargo de psicólogo judiciário, o que significou a consolidação do posto de psicólogo no sistema judiciário.

A relação entre os saberes construídos pela Psicologia, o Direito e as práticas judiciárias é 
muito antiga, mas ainda pouco conhecida no Brasil. A partir da complexidade com que foram se constituindo as regras de convivência humana, as bases da lei foram se complexificando e absorvendo cada vez mais contribuições dos diversos campos do saber.

Brito (1999) nos fala que a idéia de que todo o Direito, ou grande parte dele, está impregnado de componentes psicológicos justifica a colaboração da Psicologia com o propósito de obtenção de eficácia jurídica.

Em se tratando de violência perpetrada no lar estamos adentrando na Psicologia Jurídica aplicada à área Civil. Dessa forma podemos pensar que:

A função do profissional psi consiste em interpretar a comunicação inconsciente que ocorre na dinâmica familiar e pessoal [...] Seu objetivo é destacar e analisar os aspectos psicológicos das pessoas envolvidas, que digam respeito a questões afetivo-comportamentais da dinâmica familiar, ocultas por trás das relações processuais, e que garantam os direitos e o bem-estar da criança e/ou adolescente, a fim de auxiliar o juiz na tomada de uma decisão que melhor atenda às necessidades dessas pessoas. (SILVA, 2003, p.39)

Como afirma Miranda (1998), constituiu-se a partir de então uma nova área de prática dos psicólogos: a psicologia jurídica. O lugar ocupado por esta ainda é pouco definido. A relação entre a psicologia e as práticas jurídicas ainda se dá de forma estremecida e o lugar do psicólogo nesta área ainda está por se configurar.

No que se refere à violência doméstica, intervir na família para proteger a criança representa um dilema: qual é o limite entre a proteção aos direitos da criança e o respeito à convivência familiar? Que nível de violência intrafamiliar justifica a intervenção? Em que circunstâncias afastar uma criança de seus pais biológicos pode representar um benefício?

Pensando nesta família como doente - sustento a idéia de que famílias que maltratam têm como característica básica o sofrimento psíquico, ou ainda são portadoras de transtornos mentais evidencia-se a necessidade de auxílio, independente da decisão que vai ser tomada a posteriori. Talvez a única alternativa em algumas situações seja o afastamento, mas nunca sem antes usar de todos os recursos possíveis para a reestruturação familiar.

Quando se fala em recursos tem que se pen- sar que eles ainda são muito escassos. A maior parte das famílias não recebe apoio adequado para enfrentar a situação e ter possibilidades de revertêla. Para verificar esta realidade basta observar os casos acompanhados pelos Conselhos Tutelares, onde o que se observa é o pouco empenho dedicado aos mesmos, uma vez que de nada adianta encaminhar para tratamento e programas se não é dada uma atenção especial a estas famílias, um "empurrãozinho" para que as coisas aconteçam. Essa falta de amparo se dá tanto em relação ao núcleo familiar quanto à criança afastada. Como conseqüência, percebe-se, muitas vezes, que crianças afastadas da família por maus-tratos não retornam aos lares de origem.

Para enfrentar a violência doméstica são necessárias, além de medidas punitivas, ações que estejam voltadas para a prevenção, e, ainda, medidas de apoio que permitam, por um lado, à vítima e à sua família ter assistência social, psicológica e jurídica necessárias à recomposição após a violência sofrida e, por outro lado, que proporcionem a possibilidade de reabilitação dos agressores.

Apesar da necessidade que as famílias nestas situações têm de auxílio psicológico, há entraves para a consolidação da prática psi na instituição judiciária. Porém, hoje se sabe também que é pouco provável que haja benefícios na ação que se contenta em localizar agressores e vítimas, punir os primeiros e proteger os segundos. A violência, produto da cultura que explode em relações interpessoais, deve ser vista de modo mais abrangente.

Se a ótica é de proteção à família, a transferência da pena exclui o argumento, na medida em que a vítima e demais membros do grupo familiar do agente criminalizado serão, por extensão, também penalizados tendo, muitas vezes, que sair de seus lares para que sejam protegidos. Estas são ainda as medidas mais comuns: ou se tira o agressor, ou se afasta as crianças, colocando-as em instituições por período indeterminado. O tratamento fica para segundo plano.

As instituições que prestam serviços - jurídicos, policiais, de saúde e educação - ainda não contam, em sua maioria, com sistemas de diagnósticos e registros apropriados. A ciência avançou tremendamente, os modelos diagnósticos evoluíram significativamente e os juristas brasileiros se debatem numa questão primitiva - a questão da materialidade nos casos de maus-tratos contra crianças e adolescentes sem lesões orgânicas compatíveis. Os diagnósticos psicológicos não falam da "materialidade" esperada, tanto que os laudos de avaliação psicológica costumam ser desprezados 
nos tribunais. Estes falam de marcas que não são visíveis de forma concreta, mas que nem por isso representam menor dano ao desenvolvimento do sujeito, muito pelo contrário, são danos que, diferente de um machucado provocado por uma agressão física, podem ficar impressos para o resto da vida.

A lei no Brasil ainda exige exame de corpo de delito. No Rio Grande do Sul, os Institutos Médico-legais (IMLs) não possuem sequer uma sala reservada ou cama ginecológica para os exames. Conforme afirma Caminha (2000, p.18):

"Não podemos esperar, também, que um sujeito que está com as câmaras frigoríficas cheias de cadáveres a serem analisados, além dos costumeiros acidentes de trânsito, brigas e etc., goze de grandes talentos e delicadezas para atender crianças e adolescentes maltratados".

O perito, neste caso, é um pouco vítima, já que o Estado não lhe fornece nem condições materiais nem formação técnica compatível para o atendimento destes casos. Como produto de tais exames temos um segundo abuso igualmente traumático.

Todos estes fatores, somados ao desconhecimento e temor da sociedade frente à dinâmica das relações intrafamiliares violentas, levam as pessoas (tanto vítimas quanto agentes sociais) a evitar olhar para ela. Entretanto, é preciso assinalar que, a cada dia que passa, esses aspectos vêm sendo superados, haja visto o número cada vez maior de denúncias realizadas.

Com isso pode-se questionar: que tipo de auxílio e proteção é oferecido pelo Estado nos casos de violência doméstica? A resposta encontrada é que o sistema penal, confirmando uma tendência que não é nova, acaba por jogar na vala comum todos os conflitos domésticos, sem que se possa diferenciar os casos e com isso constatar que, em muitos deles, a ocorrência de transtornos mentais e culturas familiares que se propagam estão presentes.

Na maior parte dos casos, o trabalho do Estado encerra-se na constatação da violência sofrida e na busca da preservação da criança de outros abusos. O acompanhamento tanto do abusado como do abusador não são contemplados pelo sistema. Resta desatendida a recomendação mais importante, ou seja, a que sugere que os Estados introduzam em suas legislações nacionais processos alternativos de compensação e de consolidação para a solução dos conflitos. Estes incluiriam a possibilidade de tratamento tanto para as vítimas quanto para o abusador. O objetivo de tais propostas é restabelecer (ou estabelecer) um equilíbrio justo entre vítima e autor, prescindindo do processo penal (quando isto é possível). Assim, evitar-se-ia a estigmatização de ambos (vítima e autor), possibilitando-se uma resposta mais eficiente aos anseios das partes envolvidas, principalmente das vítimas.

Diante desse fato, constata-se no exercício da "Lei" a forte presença da punição e a pouca importância que se dá à reabilitação ou, ainda mais longe, à atenção primária, à qualidade de vida das pessoas.

Compete às equipes de Saúde da Família conhecer, discutir e buscar a identificação dos fatores de risco na população adscrita, para facilitar a definição de ações a serem desenvolvidas, com a finalidade de intervir preventivamente ou confirmar um diagnóstico, visando a adoção das medidas adequadas às diversas situações de violência intrafamiliar.

É necessário considerar a complexidade da sociedade brasileira organizada em distintos setores que devem ser envolvidos, de forma articulada, na luta contra a violência: ONGs, mídia, partidos políticos, associações de classe, associações de base, Igreja, empresariado, movimentos sociais, escolas e universidades, dentre outros.

A instrumentalização de instâncias alternativas com tal envergadura de envolvimento sócio-comunitário é o caminho mais propício para a concretização desse objetivo. Tanto mais que o sistema judiciário representa uma opção cruel e incongruente não apenas para o agressor, mas também para a própria vítima. Este tem se mostrado incapacitado para cumprir qualquer função preventiva e/ou reparatória nos casos de violência doméstica.

Este fato vem corroborar com a idéia de Cervini (1990) quando argumenta que, na gradação de opções de controle, o procedimento jurídico formal é tão-somente uma das soluções possíveis, sem dúvida a mais impessoal e onerosa, mas não necessariamente a mais eficaz, para a solução de lodosos conflitos.

Quanto ao papel do psicólogo, constata-se a necessidade de um olhar mais amplo, que contemple, além das demandas particulares de cada sujeito (tratamento do abusador e do abusado), um envolvimento maior com o social, pois não se pode descolar a violência do contexto social em que ela está inserida.

Benevides (2002) nos fala sobre a articulação entre saúde mental, direitos humanos e profissionais psi, mostrando que as situações sociais, aquelas em que se compartilham deveres e direi- 
Cesca, T.B. "O papel do psicológico jurídico na violência intrafamiliar: possíveis articulaçōes"

tos, são geralmente percebidas como pertinentes ao campo das ciências jurídicas, das ciências sociais. Ressaltando que esta clara dicotomia - de um lado o indivíduo, de outro a sociedade - não se instala sem conseqüências.

O caminho que pode conduzir a uma resposta coerente deve ser trilhado de dentro para fora do judiciário. Abri-lo passa pela valorização da vontade das vítimas, que pretendem, na verdade, ao aportar neste sistema, encontrar aí uma instância mediadora capaz de deter a escalada da violência e de assessorá-las na empreitada de repactuação de sua convivência doméstica.

Analisando formas de intervir nesta problemática, Hermam (2000) nos apresenta o exemplo do Canadá. Este país propôs soluções extraprocessuais para delitos ocorridos no seio familiar ou no meio social que o circunda, visando resolver a interação vítima-autor através de instâncias de compensação. Em tais instâncias informais buscam-se soluções através da atuação de equipe multidisciplinar em serviços comunitários visando o aconselhamento, cuidado e tratamento familiar. Fazendo com que muitos casos possam ser resolvidos sem que precisem chegar ao sistema judiciário.

Num segundo momento, em 1985, o Canadá formou a Rede Pró-Justiça Comunitária e Solução de Conflitos com o propósito de viabilizar a troca de informações, a capacitação de intermediários sociais e a instrumentalização de novas instâncias de justiça informal.

Através da rede interagem mediadores, psicólogos, advogados, docentes, investigadores sociais, administradores, pessoal da justiça penal e os que são partes no conflito, sendo dessa forma atacados vários núcleos, tais como rixas de vizinhos, reconciliação delinqüente/vítima, conflitos familiares e ambientais, violência contra a criança e o adolescente, enfim, alternativas de tratamento que evitem o processo penal e priorizem a proteção das vítimas em geral.

A experiência canadense, como um todo, embora ainda minoritária, apresenta soluções que representam uma proposta concreta de retomada, por parte da sociedade, de conflitos que lhe dizem respeito diretamente, abrindo uma trilha que reinsere autor e vítima. É muito menos onerosa que o processo formal e o encarceramento: enquanto opção alternativa, representa um dispêndio anual de dois dólares por habitante, os encargos inerentes à operacionalização do sistema penal oficial chegam a atingir mais de cem dólares por habitante/ano. Entretanto, é preciso frisar que a atuação da rede só atinge oito a dez por cento dos conflitos conhe- cidos.

Uma das opções que poderia ser adaptada à realidade brasileira e especificamente aos casos de conflito doméstico é o "Serviço de mediação comunitária", que administra a interveniência de mediadores sociais, os quais sugerem caminhos para a composição extrajudicial.

A estrutura da instância alternativa deve contar com o trabalho de mediadores leigos, comunitariamente próximos dos protagonistas do conflito, mas previamente preparados para a função por técnicos especializados, de preferência por equipe multidisciplinar (psicólogo, assistente social, advogado). Essa preparação é relevante, na medida em que os mediadores comunitários devem estar conscientes de estar lidando com um conflito delicado, bem como atentos a uma eventual escalada desse conflito, que possa porventura desaguar em conseqüências mais sérias (um homicídio, por exemplo).

É importante, ainda, que os mediadores possam contar com supervisão periódica por parte da equipe multidisciplinar. Para tanto, deve ser-lhes oportunizado trazer, ao menos a cada trinta dias, os casos sob seu atendimento à discussão grupal com outros mediadores, sob a coordenação de profissional habilitado.

A política de prevenção deve atingir, sensibilizando e capacitando, todos os atores que tenham contato com pessoas vítimas de violência nas diferentes etapas do processo. Isto inclui os profissionais de saúde, os agentes policiais, membros do Poder Judiciário, psicólogos e assistentes sociais.

A abordagem deve ser multidisciplinar, sendo que a assistência ambulatorial ou hospitalar precisa ser criteriosamente decidida pela equipe, particularizando cada caso. O trabalho junto à família é imprescindível e não deve ser apenas pontual. Essa família dever ser acompanhada durante um período que permita avaliar suas demandas, propondo-se a partir de então intervenções adequadas.

Pensando ainda no contexto brasileiro, algumas propostas neste sentido já estão sendo executadas. Estados como São Paulo, Ceará, Pernambuco, Minas Gerais, possuem algumas localidades onde estão sendo produzidos trabalhos inovadores no que diz respeito ao tratamento prestado à saúde mental e saúde da família como um todo, fazendo com que muitas questões possam ser resolvidas de forma mais humana, priorizando a saúde ao invés das punições.

Estes exemplos nos mostram tentativas de resolução de problemas que ficam mais centradas 
nas comunidades e muitas vezes não necessitam passar pelo sistema judiciário. É um caminho promissor, que trabalha com sistemas mais compartimentalizados, prestando uma atenção focalizada nas necessidades de cada população.

Dessa forma, conclui-se que a articulação entre os profissionais que trabalham com a violência intrafamiliar ainda precisa ser bastante trabalhada, embora já existam alguns movimentos neste sentido. Segundo Silva (2003), desde 1980 os juízes vêm sendo sensibilizados, através de um trabalho de esclarecimento, sobre a importância do aspecto dinâmico e emocional e sobre a compreensão do que é subjetividade, uma vez que esta visão começa a fazer parte da formação dos juízes na Escola Superior de Magistratura. Um dos pontos de entrave para este processo é o fato da rotatividade de juízes na Vara ser muito grande, dificultando o trabalho. Há diversidade de opiniões que passam pela instituição, de pessoas com diferentes orientações, desde aquele juiz que acredita na importância das questões emocionais, da doença mental e que faz cursos de aperfeiçoamento na área psi para melhor servir a população, até aquele que vê a psicologia como uma área avessa ao Direito e que este tem que se valer única e exclusivamente das normas.

O Estatuto da Criança e do Adolescente (ECA, 2002) fala sobre a importância de o juiz ser dotado de sensibilidade, a fim de poder julgar na área da infância e da juventude. E, mais do que possuir esta sensibilidade, tem o dever de agir em fina sintonia com ela em prol do bem-estar do assistido.

Quanto aos Psicólogos que optam por trabalhar com questões jurídicas acabam, muitas vezes, formando uma pele de proteção que os torna rígidos, deslocando mais para questões que dizem respeito a leis fixas, deixando de lado o olhar singular às questões trazidas por cada sujeito. Talvez pelo fato de que trabalhar com violência doméstica é trabalhar com frustrações constantes, com situações que remetem a sentimentos diversos e confusos em alguns momentos, onde o profissional que não está preparado acaba deixando-se levar por atravessamentos pessoais que o impedem de ter uma visão clara da situação apresentada.

Um novo olhar se faz necessário no entendimento desta prática, onde somente os testes psicológicos e as leis jurídicas não podem dar conta da imensidão existente na configuração familiar, uma vez que esta traz situações e sentimentos que não podem ser mensurados unicamente pelo objetivo, isto é, pela mensuração e aplicação de normas. Para isto, parcerias devem ser efetivadas e fortalecidas. Os profissionais devem estar mais flexíveis, dispostos a traçar novos percursos, criar novas alternativas que possam contemplar as demandas trazidas de forma mais saudável possível.

A violência intrafamiliar deve ser tratada e não punida. Deve-se investigar as causas, usar as pesquisas para, a partir de um trabalho em equipe, tornar viável a reestruturação familiar. $\mathrm{O}$ que se percebe é que as instâncias envolvidas nestes casos pouco fazem porque pouco acreditam em resultados positivos, tendo em vista a complexidade desta problemática. É preciso uma maior qualificação como profissional e como pessoa para que possamos trabalhar nesta área (tanto o conselheiro tutelar, como o psi, o assistente social, o juiz....).

Pensando no psicólogo como facilitador da promoção da saúde, ele deve procurar garantir os direitos fundamentais dos indivíduos, visando sua saúde mental e a busca da cidadania. Do contrário, será mais um agente repressor.

\section{REFERÊNCIAS}

BENEVIDES, R. B. Saúde Mental: a importância de se assegurarem direitos. IN: RAUTER, C; PASSOS, E; BENEVIDES, R. (Org.). Clínica e Política: Subjetividade e Violação dos Direitos Humanos. Rio de Janeiro: TeCorá, 2002.

BRITO, L. M. T. (Org.) Temas de Psicologia Jurídica. Rio de Janeiro: Dumara,1999.

CAMINHA, R. M. Maus-Tratos: o Flagelo da Infância. Cadernos de Extensão Unisinos. São Leopoldo: Editora Unisinos, p.18, 2000.

CERVINI, R. Os Processos de Descriminalização.São Paulo: Ed. Revista dos Tribunais, 1995.

ESTATUTO DA CRIANÇA E DO ADOLESCENTE (ECA). São Paulo: Malheiros Editores, 2002.

HERMANN, L. Violência Doméstica: a dor que a lei esqueceu. São Paulo: CEL-LEX, p.388, 2000.

MIRANDA, H. C. J. Psicologia e Justiça: a Psicologia e as Práticas Judiciárias na Construção do Ideal de Justiça. Revista Ciência e Profissão, São Paulo, n.18, p. 28-37, 1998.

SILVA, D. M. P. Psicologia Jurídica no Processo Civil Brasileiro. São Paulo: Casa do Psicólogo, p.39, 2003. 
Cesca, T.B. "O papel do psicológico jurídico na violência intrafamiliar: possíveis articulações"

Taís Burin Cesca é Psicóloga CRP -

07/12738. Pós-graduanda do Curso de Especialização em Psicologia Jurídica da Ulbra.

O endereço eletrônico da autora é:

tcesca@terra.com.br.

Taís Burin Cesca

O papel do psicólogo jurídico na violência intrafamiliar: possíveis articulações.

Recebido: 12/05/2004

$1^{\text {a }}$ revisão: 22/10/2004

Aceite final: 20/12/2004 